\section{Extrusión de instrumento a tejidos periapicales y resolución mediante cirugía periapical: reporte de un caso}

\section{Extrusion of instrument to periapical tissues and resolution by periapical surgery: a case report}

\begin{abstract}
Resumen
El desprendimiento de instrumentos manuales o rotatorios es una de las complicaciones comunes que se presentan al realizar un tratamiento de endodoncia. El procedimiento ideal consiste en remover el instrumento del conducto, sin embargo, existen casos en los cuales resulta imposible retirarlo; por lo cual, es necesario realizar una cirugía periapical. En este caso se explica cómo se procedió a eliminar un instrumento desprendido en el tercio apical de un primer premolar inferior derecho que fue extruido a tejidos periapicales al tratar de removerlo con ultrasonido, por este motivo se realizó una apicectomía en el órgano dental comprometido.
\end{abstract}

Palabras clave: Apicectomía; Endodoncia; Tejido periapical; Ultrasonido (fuente: DeCS BIREME).

\begin{abstract}
The fracture of manual or rotatory instruments is one of the most common complications that occurs during the root canal treatment. Removing the instrument from inside of the canal is the ideal procedure, however, there are cases in which is impossible to remove it, so, a periapical surgery is needed. In this case, we explain how an endodontic instrument fractured in the apical third of a first low premolar was extruded to periapical tissues when using ultrasound to attempt to remove it, for this reason an apicectomy was performed on the compromised dental organ.
\end{abstract}

Keywords: Apicoectomy; Endodontics; Periapical tissue; Ultrasonics (source: $\mathrm{MeSH}$ NLM).

\section{Caso Clínico}

Jesús Israel Villalpando-Lazcano ${ }^{1, a}$, Denise Constandse-Cortez ${ }^{1, a, b}$, Edgar Vázquez-Quiroga ${ }^{1, a, b}$, Diana Juana García-Zamarrón 1,a,b

${ }^{1}$ Universidad Autónoma de Ciudad Juárez, Instituto de Ciencias Biomédicas. Chihuahua, México.

a Cirujano Dentista.

${ }^{\mathrm{b}}$ Especialista en Endodoncia.

\section{Correspondencia:}

Jesús Israel Villalpando-Lazcano.

Correo electrónico: Is_villalpando@hotmail.com Av. Benjamín Franklin 4650, Zona PRONAF, 32310

Ciudad Juárez, Chihuahua, México.

\section{Coautores:}

Denise Constandse-Cortez denise.constandse@uacj.mx Edgar Vázquez-Quiroga edgarvq@gmail.com

Diana Juana García-Zamarrón

diana.zamarron@uacj.mx

\section{Editor:}

Donald Ramos-Perfecto

Universidad Nacional Mayor de San Marcos, Perú.

Conflicto de intereses: los autores declaran no tener conflictos de interés.

Fuente de financiamiento: autofinanciado.

Recibido: 08/05/19

Aceptado: 04/07/19

Publicado: 27/11/19 


\section{Introducción}

La cirugía periapical (CPA) consiste en un procedimiento quirúrgico relacionado con dientes tratados endodónticamente o con afecciones periodontales que requieren la remoción de una porción del ápice y el tratamiento endodóntico ${ }^{1}$. La CPA pertenece al campo de la cirugía endodóntica la cual incluye incisión y drenaje, obturación de perforaciones y recesiones radiculares. De acuerdo con la ESE (European Society of Endodontology), la CPA está indicada cuando radiográficamente se manifiestan signos de periodontitis apical y/o sintomatología, una vez realizado el retratamiento de conductos, en algunos casos de perforaciones a nivel radicular o de furca y cuando emergen lesiones periapicales causadas por extrusión de materiales inertes ${ }^{2}$. Según Cohen, la cirugía es la primera elección para tratar dientes con instrumentos separados cuando debido al sitio en el que se encuentran son irrecuperables ${ }^{3}$.

Los materiales utilizados durante la CPA deben ser biocompatibles cuando se colocan directamente con tejidos como pulpa, para reparación de una perforación o al utilizarse como obturación retrograda en apicectomía ${ }^{4}$. El Agregado Trióxido Mineral (MTA) es un material biocompatible compuesto por finas partículas hidrofílicas que se fijan cuando hay presencia de humedad. Varios estudios han reportado la habilidad del MTA de prevenir filtraciones, lo cual indica ser un material superior comparado con otros materiales dentales 5 . En la obturación retrógrada se ha confirmado que el MTA se asocia a una menor inflamación de tejidos adyacentes, una formación de cemento contiguo al material y una favorable regeneración de los tejidos perirradiculares ${ }^{6}$.

Este estudio tiene como objetivo mostrar uno de los tratamientos que se pueden realizar para la remoción de un instrumento fracturado y extruido a tejidos periapicales. Es indispensable tener un amplio conocimiento en cuanto a los procedimientos, indicaciones y materiales adecuados para realizar una CPA, ya que un buen manejo de esta puede asegurar el éxito del tratamiento.

\section{Reporte del caso}

Paciente de sexo femenino de 71 ańos fue referida a la clínica del posgrado de endodoncia de la Universidad Autónoma de Ciudad Juárez debido a fractura de instrumento manual (Lima Hedstroem n. ${ }^{\circ} 40$ )

La paciente se presentó asintomática sin signos patológicos evidentes, al realizar la inspección radiográfica, se observó el instrumento desprendido en el tercio apical y medio del primer premolar inferior derecho (Figura 1A).

Bajo anestesia local y aislamiento absoluto, se realizó la apertura cameral hasta localizar el conducto de la pieza comprometida. Para una mejor visualización del instrumento fracturado nos apoyamos de un microscopio operatorio dental Global (A-Series ${ }^{\mathrm{TM}}$, USA) para así proceder con la primera opción de remoción del instrumento, la cual consistió en eliminarlo por medio de técnicas con ultrasonido. Al momento de iniciar con dicho procedimiento con ayuda del ultrasonido Varios (NSK-modelo 370, USA) se observó que el instrumento cambió de posición, comprobando con un examen radiográfico que se desplazó a los tejidos periapicales (Figura 1B). Se colocó medicación intraconducto Ultracal" (Ultradent, USA) y obturación provisional para planificar otra opción de tratamiento.

Se determinó realizar una cirugía periapical como tratamiento definitivo. En la segunda cita se colocó un tapón apical con MTA Angelus" (Ángelus, Brasil) el cual fue colocado vía intraconducto con porta-MTA y compactado con condensadores Schilder (Dentsply international, Suiza) posteriormente se obturó provisionalmente. Una semana después se realizó la obturación del conducto con gutapercha y cemento sellador AH plus (Dentsply international, Suiza) y la porción cameral se selló con una obturación provisional (Figura 1C).

Durante la cuarta cita (2 semanas después) se realizó la cirugía periapical, durante la cual se utilizó anestesia local (articaina 4\% con epinefrina 1:100 000) colocando un cartucho para bloquear el nervio dentario inferior y



Figura 1. A. Radiografía inicial en donde se observa instrumento manual desprendido en tercio medio y apical. B. Radiografía en donde se observa instrumento extruido a tejido periapical. C. Radiografía en donde se observa la obturación con MTA en porción apical y en tercio medio obturación con gutapercha y cemento sellador AH plus 
el nervio lingual, posteriormente se colocó un cartucho anestesiando el nervio mentoniano. Se realizó la incisión intrasulcular y levantando el colgajo, se realizó la ostectomía utilizando una fresa redonda de carburo de alta velocidad n. ${ }^{\circ} 8$ hasta localizar el ápice del órgano dental (Figura 2A), se eliminó el instrumento extruido y la porción apical afectada por el mismo con una fresa de cirugía zekrya (Dentsply Maillefer, USA) (Figura 2B) y con ayuda de un microespejo se revisó la porción que se encontraba sellada con el MTA (Figura 2C). Se colocó ROEKO Gelatamp' (Coltene, Brasil) y se reposicionó el colgajo utilizando sutura de nylon 4-0.

Una semana después de la cirugía se retiraron las suturas y se realizaron estudios radiográficos de control (Figura $3 \mathrm{~A})$, después de tres meses la paciente no presentó sintomatología (Figura 3B).

\section{Discusión}

La separación de instrumentos durante el tratamiento endodóntico es relativamente frecuente y puede poner en riesgo la tasa de éxito del tratamiento de conductos
7, a pesar de que este tipo de accidente se puede solucionar mediante maniobras por medio de ultrasonido o sistemas específicos de remoción de instrumentos desprendidos ${ }^{8}$, lo primero que se debe evaluar es en qué zona del conducto se produjo tal separación ya que si hay un desprendimiento que involucre la salida del instrumento a tejidos periapicales, el plan de tratamiento cambiará y será indispensable pensar en un plan quirúrgico 9 . Vineet Agrawal et al. ${ }^{8}$ mencionan que hay diversos factores que predisponen la fractura de las limas rotatorias y manuales que van desde el proceso de fabricación de los instrumentos, la forma en la que los utilizamos, hasta las variaciones anatómicas radiculares. Además, mencionan que un desprendimiento de algún instrumento dentro del canal no siempre va a llevar al fracaso del tratamiento.

La obturación apical con MTA, en este caso, fue realizada intraconducto ya que se decidió aprovechar la amplitud de este durante el procedimiento, para poder reducir el tiempo de la cirugía. Se decidió llevar el tratamiento por medio de obturación con MTA por el buen sellado ante



Figura 2. A. Osteotomía y localización de la porción apical dañada. B. Ventana ósea quirúrgica una vez realizada la resección apical. C. Revisión del sellado del MTA con microespejo en la porción radicular remanente

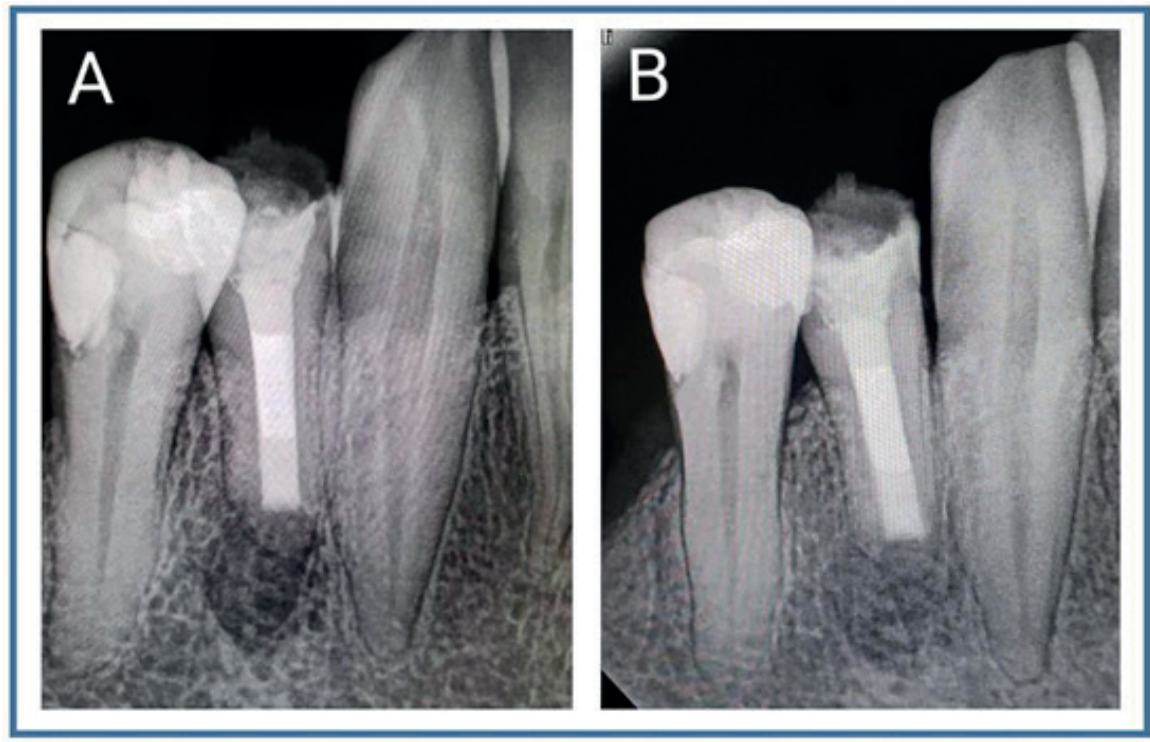

Figura 3. (A) Radiografía 1 semana posterior a la cirugía periapical. (B) Radiografía de control 3 meses después. 
la microfiltración y su biocompatibilidad, además se ha confirmado que el MTA se asocia a una menor inflamación de tejidos adyacentes, una formación de cemento contiguo al material y una favorable regeneración de los tejidos perirradiculares ${ }^{10}$, posteriormente se realizó la apicectomía debido al daño de la pared radicular en la porción apical, para tener un mejor pronóstico. Borras Aviño et al. ${ }^{11}$ mencionan que ante un grave deterioro radicular es recomendado rellenar totalmente el conducto con MTA, en este caso se determinó que no era viable debido a la perdida de estructura coronal y la necesidad de colocación de un endoposte para la adecuada rehabilitación de la pieza, además sería complicada la eliminación de este material debido a su dureza.

En este caso se decidió utilizar MTA sobre otros materiales que están indicados para lograr la formación de una barrera apical durante la realización de una apicectomía, debido a sus excelentes propiedades y características descritas anteriormente, además cabe mencionar que este material fragua en presencia de humedad y debido a la naturaleza que conlleva la cirugía periapical en donde están involucrados fluidos tales como la sangre, líquidos tisulares, etc. se consideró que este factor fue clave a la hora de la elección del material para aumentar la tasa de éxito ${ }^{12}$.

Se ha revisado la literatura y son escasos los artículos que reúnan las características que se pueden observar en este caso, por ello queremos compartir esta experiencia para que sirva para futuros estudios ya que los accidentes operatorios son un factor que debe ser considerado en nuestra práctica profesional debido a que el instrumental va sufriendo desgaste, fatiga, corrosión, degeneración, etc. lo cual es importante solucionar y más aún aprender de ello.

\section{Referencias bibliográficas}

1. Tobon CD. Indicaciones y contraindicaciones de la cirugía endodóntica. Rev Fac Odontol Univ Antioq. 1994;6(1):45-48.
2. Von-Arx T. Apical Surgery: A review of current techniques and outcome. Saudí Dent J. 2011;23(1):9-15.

3. Hargreaves K, Berman L, Cohen S. Vías de la pulpa. 10. ed. Barcelona: Elsevier; 2011.

4. Nehal YY, Ibrahim HE, Salwa MA. Histopathological evaluation of periodontium after repairing furcation perforation with MTA and Biodentine. Ped dent J. 2018;28(1):33-39.

5. Ebtesam OA. Ashraf MA. Salma HE. A comparative study of the physicochemical properties of hesperidin, MTA-Angelus and calcium hydroxide as pulp capping materials. Saudí Dent J. 2019;31(2):219-227.

6. Zabala MP. El agregado de trióxido mineral (MTA) en endodoncia. Odont Act. 2017;2(3):11-17.

7. Suter B, Lussi A, Sequeira P. Probability of removing fractured instruments from root canals. Int Endod J. 2005;38:112-123.

8. Vineet A, Sonali K, Mukesh P. Ultrasonic Technique to Retrieve a Rotary Nickel-Titanium File Broken Beyond the Apex and a Stainless Steel File from the Root Canal of a Mandibular Molar: A Case Report. J Dent (Tehran). 2015;12(7):532-536.

9. Adil G, Bandish P, Gaurav P, Aliya S. Surgical Removal of Fractured Endodontic Instrument in the Periapex of Mandibular First Molar. J Int Oral Health 2014;6(4):85-88.

10. Obando-Pereda G, Torres-Chavez K, Salas-Beltran H, Hofling JF. Análisis de la composición química, capacidad de sellado apical y propiedades antimicrobianas del MTA y del cemento portland. Endo. 2009;27(3):111120.

11. Borrás AC, Catalá PM, Estrela SF. Utilización del MTA en el tratamiento de situaciones complejas de inmadurez radicular. Odontol Pediatr. 2006;14(3):76-81.

12. Duarte MA, Marciano MA, Vivan RR, Tanomaru FM, Tanomaru JM, Camilleri J. Tricalcium silicate-based cements: properties and modifications. Braz Oral Res. 2018;32(1):111-118. 